Wei-Dong Mi MD, *

Tetsuhiro Sakai MD, Satoshi Takahashi MD, Akitomo Matsuki MD

\section{Haemodynamic and electroencephalograph responses to intubation during induction with propofol or propofol/fentanyl}

Purpose: To observe the changes in EEG bispectral index (BIS), 95\% spectral edge frequency ( $95 \%$ SEF) and median frequency (MF) with haemodynamic changes to intubation during induction with propofol or propofol and $2 \mu \mathrm{g}^{\mathrm{kg}} \mathrm{g}^{-1}$ fentanyliv.

Methods: Twenty four ASA I-Il patients were randomized to receive either propofol infusion preceded by normal saline (group $P, n=12$ ) or propofol preceded by $2 \mu \mathrm{g}^{-1}$ fentanyl (group PF, $n=12$ ). Intubation was performed five minutes after maintenance of BIS within $45 \pm 5$. EEG and haemodynamic variables were recorded at before induction, and before and after intubation.

Results: Haemodynamic responses to intubation were greater in group $P$ than in group $P F(P<0.05)$. Postintubation SBP, DBP and HR increased, compared with preinduction values, more in group $P$ than in group PF. Postintubation BIS values increased from $45.5 \pm 3.5$ and $44.2 \pm 4.1$ to $51.1 \pm 4.1$ and $50.9 \pm 5.3$ in groups $\mathrm{P}$ and $\mathrm{PF}$, respectively, compared with preintubation values. The BIS values were not different between treatment groups before and after intubation, and $95 \%$ SEF and MF values did not increase after intubation.

Conclusion: Fentanyl, $2 \mu \mathrm{g}^{\mathrm{kg}}{ }^{-1} \mathrm{i}$, blunted the haemodynamic responses to intubation, but failed to attenuate the arousal of cerebral cortical activity. The different haemodynamic responses postintubation but similar BIS and $95 \%$ SEF changes in the two groups suggest that BIS or $95 \%$ SEF cannot predict the haemodynamic responses to intubation during anaesthesia induction with propofol and fentanyl.

Objectif : Observer les altérations de l'index ÉEG bispectral (BIS), sur la fréquence spectrale de marge (95\% SEF) et la fréquence moyenne (FM) causées par les changements hémodynamiques de l'intubation pendant l'induction au propofol ou au propofol associé au fentanyl $2 \mu \mathrm{g} \mathrm{kg}^{-1}$ iv.

Méthodes : Vingt-quatre patients ASA I- I I ont reçu aléatoirement soit une perfusion de propofol précédée de sol. phys. (groupe $P, n=12$ ) ou de propofol précédé de fentanyl $2 \mu \mathrm{gg}^{-1}$ (groupe $P F_{1} n=12$ ). On intubait cinq minutes après la stabilisation du BIS entre $45 \pm 5$. L'ÉEg et les variables hémodynamiques étaient enregistrées avant l'induction, et avant et apres l'intubation.

Résultats : Les réponses hémodynamiques à l'intubation étaient plus importantes dans le groupe $\mathrm{P}$ que dans le groupe PF $(P<0,05)$. Après l'intubation, la pression artérielle systolique et diastolique et la Fc augmentaient comparativement aux valeurs de préinduction, mais plus dans le groupe $P$ que dans le groupe PF. Après l'intubation, les valeurs du BIS augmentaient de $45 \pm 3,5$ à $51 \pm 4$. I dans le groupe $P$ et de $44 \pm 4,1$ à $50,9 \pm 5,3$ dans les groupes PF comparativement aux valeurs précédant l'intubation ; les valeurs SEF $95 \%$ et MF n'augmentaient pas après l'extubation.

Conclusion : Le fentanyl $2 \mu \mathrm{g} \mathrm{kg}^{-}{ }^{\text {iv }}$ atténue les réponses hémodynamiques à l'intubation mais ne parvient pas à atténuer l'éveil de l'activité corticale cérébrale. La différence des réponses hémodynamiques postintubation mais la similarité des changements de BIS et de SEF95\% dans les deux groupes suggèrent que BIS et SEF 95\% ne peuvent prédire les réponses hémodynamique à l'intubation pendant l'induction de l'anesthésie au propofol et au fentanyl.

From the Department of Anaesthesiology, University of Hirosaki, School of Medicine, Hirosaki, 036, Japan. Address correspondence to: Tetsuhiro Sakai MD. Phone: 81-172-39-5111; Fax: 81-172-39-5112.

*Present address of Wei-Dong Mi MD; Department of Anaesthesiology, Chinese PLA General Hospital, 28 Fu-Xing Road, Beijing, 100853, China. Accepted for publication October 9, 1997. 
$M$ ONITORING the raw EEG during clinical anaesthesia has been largely unsuccessful due to the complex influences of various anaesthetic regimens and the difficulty of interpreting the complicated EEG signal. Recently, a new processed EEG parameter, bispectral index (BIS) which determines both EEG linear and nonlinear (phase and harmonic) components, has been proposed as a measure of anaesthetic effect. ${ }^{1-3}$ The BIS reflects cerebral cortical activity well, 4,5 and is altered when a noxious stimulus is perceived by the brain at some anaesthetic levels. Opioids attenuate noxious stimulation at several levels of the sensory pathway. Thus, they should prevent lightening in the patient's hypnotic state resulting from noxious stimulation, just as they prevent the haemodynamic response to surgical stimulation. In this study, we determined the changes of BIS as well as spectral edge frequency (SEF) and median frequency (MF), and the association between these EEG variables and the haemodynamic responses to laryngoscopy and intubation after anaesthesia induction with propofol with or without fentanyl.

\section{Methods}

Following approval from the Institutional Human Studies Committee and informed consent, 24 ASA I or II patients, age 17-54 yr were studied. Patients were excluded if they had a history of hypertension or neurological deficits, were receiving cardiovascular or neuropsychiatric medicine, or intubation was expected to be difficult. Patients were randomly allocated into two groups, 12 in each, and the experiments were conducted in a double blind fashion. One group received propofol alone, by infusion, (group $\mathrm{P}$ ) and the other received propofol preceded by $2 \mu \mathrm{g} \cdot \mathrm{kg}^{-1}$ fentanyl (group PF). Sedative drugs were not given preoperatively. Patients were continuously monitored with an electrocardiogram and pulse oximeter. A venous catheter was inserted for drug and fluid administration, and a catheter into the radial artery for continuous monitoring of arterial blood pressure. All Patients received a fluid load of $5 \mathrm{mg} \cdot \mathrm{kg}^{-1}$ Ringer's Lactate over $15 \mathrm{~min}$. The EEG was monitored continuously. After preparation of the skin, four disposable silver-silver chloride electrodes (Zipprep, Aspect Medical System, MA, USA) were placed on the outer sides of both malar bones (Atl and At2) with Fpz as the reference and $\mathrm{Fp} 2$ as the ground. Impedance of the electrodes was kept $<2000$ ohms. The BIS, SEF and MF were measured using a microprocessor-based, 2-channel EEG monitor (A-1050, Aspect Medical Systems, Natick, MA, USA). The EEG parameters were calculated at five second epochs and recorded at 15-sec intervals automatically. All data were printed immediately with an
Aspect printer. After breathing $\mathrm{O}_{2}$ for three minutes, anaesthesia was induced with a constant rate infusion $30 \mathrm{mg} \cdot \mathrm{kg}^{-1} \cdot \mathrm{hr}^{-1}$ propofol using a syringe pump until the BIS value reached $45 \pm 5$ and then the rate was reduced $\left(0.5 \mathrm{mg} \cdot \mathrm{kg}^{-1} .20 \mathrm{sec}^{-1}\right)$ to maintain the value within this range for the five min prior to intubation. Intubation was facilitated by $0.1 \mathrm{mg} \cdot \mathrm{kg}^{-1}$ vecuronium and the time from inserting the laryngoscope to finishing intubation did not exceed $30 \mathrm{sec}$. The dose of propofol used for induction and total dose used were recorded. Fentanyl $2 \mu \mathrm{g} \cdot \mathrm{kg}^{-1}$ in group PF, or normal saline with the same volume per $\mathrm{kg}$ in group $\mathrm{P}$, was injected as a bolus two minutes before starting the infusion of propofol. Both the patient and the anaesthetist who performed intubation were blinded to the administration of fentanyl or normal saline. The lungs were ventilated with $\mathrm{O}_{2} 100 \%$ by a ventilator at rate of $12 \cdot \mathrm{min}^{-1}$ and tidal volume of $10 \mathrm{ml} \cdot \mathrm{kg}^{-1}$. Propofol was infused at the same rate as before intubation, and no other procedure was performed within three minutes following intubation. The baseline values of EEG parameters, systolic blood pressure (SBP), diastolic blood pressure (DBP) and heart rate (HR) were obtained from three minute average values before fentanyl or normal saline.

The values just before laryngoscopy for intubation were defined as preintubation values and the highest values for EEG or haemodynamic parameter during laryngoscopy and intubation, and within three minutes of intubation as the postintubation value.

Patients were questioned about awareness during anesthesia post-operatively. All results are expressed as mean $\pm S D$. In each group, we compared the values for each parameter between three endpoints (baseline, preintubation and postintubation) using repeatedmeasures analysis of variance, followed by Scheffe F-test. Between groups, the data were analysed with ANOVA at each endpoint. $P<0.05$ was considered statistically significant.

\section{Results}

There were no differences in age, body weight, or height between groups. No differences were found in baseline SBP, DBP, HR and EEG variables between two groups (Table I). Fentanyl, $2 \mu \mathrm{g} \cdot \mathrm{kg}^{-1}$, had no effect on the baseline EEG. There were no differences in the propofol doses required before intubation (P: $15.6 \pm 4.3 \mathrm{ml}, \mathrm{P} / \mathrm{F}: 14.3 \pm 3.9 \mathrm{ml}$ ) or in the total dose of propofol (P: $22.1 \pm 5.4 \mathrm{ml}$, PF: $21.5 \pm 5.1 \mathrm{ml}$ ). between the two groups. Propofol alone or preceded by fentanyl, decreased SBP and DBP at preintubation, but no difference was found between the two groups (Table I, $P>0.05$ ). At preintubation, HR was slowed $16 \%$ in group PF (from 71.9 \pm 8.8 to $61.8 \pm 4.7 \mathrm{bpm}$, 
TABLE I Haemodynamic and EEG variables at threc endpoints during anaesthetic induction

\begin{tabular}{|c|c|c|c|c|c|c|}
\hline & \multicolumn{2}{|c|}{ Baseline } & \multicolumn{2}{|c|}{ Preintubation } & \multicolumn{2}{|c|}{ Postintubation } \\
\hline & group $P$ & group $P F$ & group $P$ & group $P F$ & group $P$ & group $P F$ \\
\hline SBP (mmHg) & $124.1 \pm 13.3$ & $130.1 \pm 12.9$ & $100.2 \pm 9.4^{*}$ & $97.2 \pm 7.6^{*}$ & $156.3 \pm 21.1^{\star \dagger}$ & $133.1 \pm 165^{\S \dagger}$ \\
\hline $\mathrm{DBP}(\mathrm{mmHg})$ & $72.2 \pm 9.4$ & $70.3 \pm 10.3$ & $55.8 \pm 7.6^{*}$ & $52.8 \pm 4.8^{*}$ & $90.3 \pm 16.3^{\star \dagger}$ & $76.7 \pm 13.8 \pm t$ \\
\hline HR (bpm) & $69.3 \pm 11.1$ & $71.9 \pm 8.8$ & $68.3 \pm 10.9$ & $61.8 \pm 4.7^{*}$ & $91.8 \pm 15.8^{\star \dagger}$ & $71.5 \pm 10.6^{\$ t}$ \\
\hline BIS & $94.9 \pm 2.3$ & $94.5 \pm 2.8$ & $45.5 \pm 3.5^{*}$ & $44.2 \pm 4.1^{*}$ & $51.1 \pm 4.1 * 1$ & $50.9 \pm 5.3^{* \dagger}$ \\
\hline $\operatorname{SEF}(\mathrm{HZ})$ & $19.5 \pm 4.0$ & $19.4 \pm 3.3$ & $15.1 \pm 1.9^{*}$ & $14.7 \pm 2.4^{*}$ & $16.3 \pm 2.1$ & $15.2 \pm 2.3^{\star}$ \\
\hline $\mathrm{MF}(\mathrm{HZ})$ & $5.1 \pm 1.4$ & $5.3 \pm 2.2$ & $3.9 \pm 2.1$ & $3.8 \pm 2.3$ & $5.5 \pm 2.7$ & $4.8 \pm 2.3$ \\
\hline
\end{tabular}

Mean + SD

${ }^{*} P<0.01$ versus baseline; ${ }^{\dagger} P<0.01$ versus preintubation; ${ }^{\ddagger} P<0.05, \$ P<0.01$ versus between two groups

EEG: electroencephalographic; SBP: systolic blood pressure; DBP: diastolic blood pressure; HR: heart rate; BIS: bispectral index; SEF: spectral edge frequency; MF: median frequency.

$P<0.01)$. The postintubation haemodynamic responses to laryngoscopy and intubation were greater in group $P$ than in group PF. $(P<0.01)$ The haemodynamic variables were not different compared with those before induction in group PF (SBP: $2.3 \%$ increased, DBP: $9.1 \%$ increased, HR: $0.6 \%$ decreased), although SBP and DBP were increased $36.9 \%, 45.3 \%$, respectively, from preintubation. The SBP, DBP and HR in group $P$ were markedly increased $(25.8 \%, 25.0 \%$ and $32.4 \%$ vs baseline, $56.0 \%, 61.8 \%$ and $34.4 \%$ vs preintubation) in comparison with baseline and preintubation (Table I).

The EEG responses to intubation showed no difference between the two groups (Table I). The preintubation BIS value was $45.5 \pm 3.5$ in group $P$ and $44.2 \pm 4.1$ in group PF $(P>0.05)$. The stimulation of laryngoscopy and intubation increased BIS to $51.1 \pm 4.1$ in group $P$ and to $50.9 \pm 5.3$ in group PF, both of which were higher than the values before intubation $(P<0.01)$. The BIS values postintubation were not different between the two groups $(P>0.05)$. The SEF in the two groups was also reduced at preintubation. However, laryngoscopy and intubation did not increased it in either group. The MF showed no changes at endpoints preintubation or postintubation compared with preinduction.

\section{Discussion}

Our results demonstrate that administration of $2 \mu \mathrm{g} \cdot \mathrm{kg}^{-1}$ fentanyl iv, $10 \mathrm{~min}$ before intubation after propofol, $143 \pm 39 \mathrm{mg} i v$, blunted the postintubation haemodynamic responses without affecting the cortical activity. Similar to our findings, Billard et al..$^{6}$ demonstrated that $2 \mu \mathrm{g} \cdot \mathrm{kg}^{-1}$ fentanyl administered with propofol decreased the blood pressure and heart rate responses to intubation. We used a fentanyl or normal saline bolus iv two minutes before commencing propofol infusion. Propofol was infused at a rate of $30 \mathrm{mg} \cdot \mathrm{kg}^{-1} \cdot \mathrm{hr}^{-1}$ for three minutes to reduce the BIS value to $45 \pm 5$.
Intubation was performed after maintaining BIS value at $\mathbf{4 5} \pm \mathbf{5}$ for five minutes (10 min after fentanyl administration), a duration considered adequate for achieving plateau of the pharmacodynamic effect of fentanyl on central nervous system. ${ }^{6}$

The neural reflexes leading to haemodynamic responses elicited by laryngoscopy and intubation occur predominantly at the subcortical level (brain stem and hypothalamus) and do not necessarily require input from the cortex. The afferent receptors and fibres which mediate these reflexes are not nociceptive. ${ }^{7,8}$ Therefore, ablation of the nociceptive stimulation by opioids is not the primary mechanism of blunting of these responses. ${ }^{9}$ Different doses of opioids may, therefore, be necessary for blunting the different responses in the central nervous system. Fentanyl, $2 \mu \mathrm{g} \cdot \mathrm{kg}^{-1} i v$, administered with propofol attenuated the haemodynamic responses to intubation in our patients but did not affect the cortical activity as measured by BIS, SEF and MF. Propofol, $156 \pm 43 \mathrm{mg} i v$, administered without fentanyl before intubation was ineffective in attenuating these haemodynamic responses. Billard $e t a l$. demonstrated that during induction with propofol/fentanyl, 2-3.5 $\mathrm{mg} \cdot \mathrm{kg}^{-1}$ propofol $i v$ did not prevent the haemodynamic responses to intubation, suggesting that the subcortical centres responsible for haemodynamic responses were not suppressed with increasing doses of propofol. ${ }^{10}$

Just before laryngoscopy and intubation, the degree of cortical depression as assessed by the BIS, 95\% SEF and MF was similar in the two treatment groups. The subsequent similar changes in these EEG parameters with laryngoscopy and intubation suggest that there is no difference in cortical antinociception with or without fentanyl. Our results indicate that $2 \mu \mathrm{g} \cdot \mathrm{kg}^{-1}$ fentanyl is not adequate to blunt the nociceptive stimulation reaching the cortex. Since the addition of fentanyl to propofol does not attenuate input to the pathways for the haemodynamic and 
cortical responses in a parallel manner, recall may be possible during induction with either small doses of propofol or in tolerant patients with blunting of the haemodynamic responses.

Among the three EEG parameters studied, BIS appears to be the most sensitive indicator of cortical activity to noxious stimulation. Median frequency failed to show any changes throughout the process of induction and intubation with large interindividual variability. Spectral edge frequency decreased with induction, but demonstrated no alteration following intubation in either group. Our results suggest that BIS and 95\% SEF cannot predict haemodynamic responses as these EEG parameters represent cortical activity. Kearse et al. stated that BIS predicted the haemodynamic responses to intubation when thiopentone and opioids were used for induction of anaesthesia. ${ }^{9}$ However, in another study they found that the BIS did not predict the haemodynamic responses during induction with propofol." Therefore, we propose that BIS in conjunction with haemodynamic monitoring can serve as useful measures of the depression of cortical activity and haemodynamic stability, respectively.

In conclusion, $2 \mu \mathrm{g} \cdot \mathrm{kg}^{-1}$ fentanyl $i v$, in conjunction with propofol was effective in blunting the haemodynamic responses to intubation without attenuating cortical activity represented by the BIS and 95\% SEF. Cerebral cortical activity as measured by the BIS and 95\% SEF does not change in parallel with the haemodynamic responses following laryngoscopy and intubation.

\section{Acknowledgments}

We are grateful to Dr. John W.R. McIntyre, Emeritus Professor of Anaesthesia, University of Alberta, Edmonton, Canada, for critically reviewing the manuscript and providing us with his valuable comments.

\section{References}

1 Kearse LA Jr, Manberg P, Chamoun N, Debros F, ZaslapskyA. Bispectral analysis of the electroencephalogram correlates with patient movement to skin incision during propofol/nitrous oxide anesthesia.

Anesthesiology 1994; 81: 1365-70.

2 Vernon JM, Lang E, Sebel PS, Manberg P. Prediction of movement using bispectral electroencephalographic analysis during propofol/alfentanil or isoflurane alfentanil anesthesia. Anesth Analg 1995; 80: 780-5.

3 Leslie K, Sessler DI, Schroeder M, Walters K. Propofol blood concentration and the bispectral index predict suppression of learning during propofol/epidural anesthesia in volunteers. Anesth Analg 1995; 81: 1269-74.

4 Doi M, Gajraj RJ, Mantzaridis $H$, Kenny GNC. Relationship between calculated blood concentration of propofol and electrophysiological variables during emergence from anaesthesia: comparison of bispectral index, spectral edge frequency, median frequency and auditory evoked potential index. $\mathrm{Br}$ J Anaesth 1997; 78: 180-4.

5 Liu J, Singh H, White PF. Electroencephalographic bispectral index correlates with intraoperative recall and depth of propofol-induced sedation. Anesth Analg 1997; 84: 185-9.

6 Billard V, Moulla $F$, Bourgain JL, Megnigbeto A, Stanski DR. Hemodynamic response to induction and intubation. Propofol/fentanyl interaction. Anesthesiology 1994; 81: 1384-93.

7 Widdicombe JG. Receptors in the trachea and bronchi of the cat. J Physiol (Lond) 1954; 123: 71-104.

8 Boushey HA, Richardson PS, Widdicombe JG, Wise JCM. The response of laryngeal afferent fibres to mechanical and chemical stimuli. J Physiol (Lond) 1974; 240: 153-75.

9 Kearse LA Jr, Manberg P, DeBros F, Chamoun N, Sinai $V$. Bispectral analysis of the electroencephalogram during induction of anesthesia may predict hemodynamic responses to laryngoscopy and intubation.

Electroenceph Clin Neurophysiol 1994; 90: 194-200.

10 Rampil IJ, Matteo RS. Changes in EEG spectral edge frequency correlate with the hemodynamic response to laryngoscopy and intubation. Anesthesiology 1987; 67: 139-42.

11 Lui $P W$, Wang $H$, Kearse LA. The bispectral index does not predict hemodynamic responses to laryngoscopy and intubation during propofol-inducted EEG burst suppression. Anesthesiology 1996; 85: Al75. 